Research article

\title{
Health status of the population in the Republic of Moldova: a territorial perspective
}

\author{
Silvia Suvac ${ }^{1 凶}$ \\ ${ }^{1}$ Academy of Economic Studies of Moldova (University), Doctoral School of AESM, Republic of Moldova.
}

\begin{abstract}
One of the main components of the population quality is health. This study approaches health from the geodemographic point of view, in order to emphasize the population quality aspects. The progressive analysis of the demographic population health indicators points out the causes of increasing or decreasing population health. The territorial analysis highlights the districts where the population health is lower or higher. So there can be outlined some causes at the regional and local levels. This research could be used for the elaboration of some demographic policies in order to improve or keep a high level of the population's health in the Republic of Moldova. The population health is a necessity for the economic development of the country.

Keywords: population quality, health, mortality, life expectancy at birth.
\end{abstract}

\section{Introduction}

Population health represents one of the most important research subjects in different fields of study, as for example: medicine, epidemiology, psychology etc. Each researcher approaches population health in terms of his own object of study. During the last period the interest in population health has increased, also, for researches from other fields of study, as for example: economy, geography, demography etc. In this way, there appeared new sciences in the frame of this large research field of "health": health economy, medical sociology and medical geography. The interest of geographers in studying population health leads to the necessity to evaluate different medical phenomena in space and to deduce the causes of its appearance, pointing out territorial disparities and factors of risk in different geographical areas. In studying population quality, it is unavoidable to evaluate the population health, because this

\footnotetext{
CORRESPONDENCE:

$\bowtie$ str. Bănulescu Bodoni 61, MD 2005, Chișinău, R. Moldova

@ godonoagasilvia@gmail.com
} 
category plays an important part in forming population quality, together with other categories, such as: education, culture and demography. The analysis of the four categories that define population quality can lead to the complete evaluation of the Republic of Moldova population quality, both in space and in time.

\section{Methods and Methodology}

One of the geographic works that analyses in detail many demographic indicators is the paper published in Romania by Liliana Dumitrache, called "Starea de sănătate a populației României", which investigates the health conditions of the Romanian people from the geographic point of view. She analyses more different health demographic indicators, both partially and chronologically: mortality, infant mortality, life expectancy at birth, general peculiarities of the mortality and morbidity models, factors that determined territorial and progressive changes [1]. Thanks to such works, in the frame of geographical branches there appeared a new direction of study - ",medical geography". The study object of this subject is ",health" or "medical services". Geographers and demographers have recently discovered a new topic of interest: the qualitative level of population. The idea of this approach appeared in the first half of the $\mathrm{XIX}^{\text {th }}$ century and developed through three theoretical study directions: eugenics (Fairchild 1939, Thomilson 1965 etc.), economic and demographic (Foteeva 1984, Medkov 1987 etc.) and human capital (Becker and Lewis 1973, Shultz Th.W. 1981 etc.). When analysing all the points of view of the scientific concept of "population quality", it is important to notice that ",health" is present in all approaches of different researchers. In this way, it is clear that the population's health state is one of the components of "population quality". The importance of studying health in the frame of population quality research lies in the fact that health represents the qualitative base for the next young people's accomplishments, the longevity of life, the possibility to create a united family, the professional activity and also the creative and social-political activities. The geographical study of "population quality", including ",health" study, leads to progressive and territorial analyses, in this way, determining the factors of the progressive trend and the causes of territorial differences of the population quality as a scientific notion.

In order to emphasize correctly the general population health condition as a component of the population quality we calculated the health index, reveals the changes in time and space of the population health. The method of calculating this index is described in the next formula:

$$
\mathrm{J}_{\mathrm{ij}}=1-\frac{\mathrm{X}_{\mathrm{j}, \mathrm{opt}}-\mathrm{X}_{\mathrm{i}, \mathrm{j}}}{\mathrm{X}_{\mathrm{i}, \mathrm{opt}}-\mathrm{X}_{\mathrm{i}, \mathrm{min}}},
$$


where: $\mathrm{J}_{\mathrm{i} j}-$ the analyzed demographic indicator index, $\mathrm{X}_{\mathrm{j}, \mathrm{opt}}$ - the optimal value of the analyzed indicator, $X_{i, j}$ - the real value of the analyzed indicator in that year, $\mathrm{X}_{\mathrm{i}, \mathrm{min}}$ - the minimum value of the analyzed indicator. The health index will be calculated as the arithmetical mean of the three indexes determined using the above mentioned formula. In this way, the following demographic indicators were chosen: mortality rate, infant mortality rate, life expectancy at birth. The used method is argued by the Russian economist A.A. Sagradov, who mentioned in one of his articles that the arithmetical mean could be a more relevant method in analyzing the qualitative level of population, because this value will describe key-aspects of the population activity more completely and will reflect the components of population reproduction more obviously (Sagradov, 2001, p.181).

\section{Results and Discussions}

In order to determine the qualitative level of the population health three health demographic indicators were used. The indicators were chosen according to their importance in evaluating the population health from the perspective of population quality. At the first view, these indicators seem to be quite generalized, but they include other useful indicators in evaluating the population quality level of a country or region.

The first analyzed indicator is the mortality rate. This indicator clearly reveals the evolution trend of the general health state of the population. In this way, the analysis of the mortality rate is a starting point in the process of more deeply evaluating the population health state, which is one of the main categories that form population's health quality of a country.

The evolution of the mortality rate in the Republic of Moldova, registered increasing values between 1990 and 1995, from $9.7 \%$ o to $12.2 \%$. It was a period of economic and demographic transition after Moldova gained its independence in 1990. After 1995, the mortality rate decreased to $10.9 \%$ in 1998, and again rose during the next 7 years. So, in 2005, the mortality rate registered the maximum value of the analyzed period $-12.4 \%$. This fact was caused by the difficult demographic and economic transition period. Starting with 2005, the mortality rate registered a general trend of slowly decrease, punctually disturbed by insignificant increases. In 2015 the mortality rate was of $11.2 \%$, higher with $13.4 \%$ than in 1990 . This unstable situation from one year to another, but with a general increasing trend, tells us about the health state of the population in the Republic of Moldova, which experiences a process of worsening. It is also important to mention that the aging population process contributes to the higher values of the mortality rate.

It is well known that the male mortality is higher than the female one. This fact is also present in the Republic of Moldova. During the whole analysed period, 
the male mortality is higher than the female one. So, the lowest differences are registered in 1990 (1.1\% in favour of females). During the next period, the difference is of about $1-2 \%$. This fact is caused by male over-mortality, typical of many countries, especially of post-Soviet states. The known causes of this phenomenon are: the effects of the World War II, the practice of bad habits, men have more dangerous jobs, they are more frequently subject to accidents; moreover, the most important cause for the last period is the higher life expectancy at birth for females in comparison to males. This is a biological difference, because women are more resistant to infections and degenerative diseases. A specific cause for the Republic of Moldova is the differences between males' and females' culture of addressing doctors. The publication called "The analysis of the population health state in the Republic of Moldova, through statistics, for the period of 2005-2009", mentions that men call to the medical services of a specialist with $5.2 \%$ less than women and with $1.2 \%$ less than women resort to medical services provided by hospitals and pharmacies (Grama, 2010, pag.15).

The next evaluated indicator is the infant mortality rate. This demographic indicator is a specific qualitative one, because it is influenced by some sanitary, economic, educational, social and cultural factors, which represent other qualitative population characteristics. So, infant mortality is an indicator that reflects the development level of a country, the life quality of a population and also the population's health quality. The analysis of the evolution of the infant mortality rate reveals a general decreasing trend, which tells us about a better situation in the country. A possible explanation for this phenomenon is the implementation of many national programs in the field of perinatology, genetics, alimentation, combating respiratory and acute diarrhoea diseases, components that are very important in decreasing the number of deaths under the age of 1 year old. Also, it is important to mention that between 1990 and 1994 the values of this indicator rise from 19\%o to $22.6 \%$, mainly because of the unfavourable economic situation, limited access to medical institutions, bad conditions of life etc. After 1994, the infant mortality rate dropped due to the improvement of the medical system, the higher accessibility to medical institutions, the raising of educational and informational level of parents, both in rural and urban areas etc. So, the infant mortality rate during the next decade fell to about half, from $22.6 \%$ in 1994 to $12.2 \%$ in 2004 . Also, it is important to mention that in 2008 and 2009 the indicator's value increased again. This fact is linked with the recommendation of the World Health Organization to count the number of deaths under 1 year old, from the age of 22 weeks and the weight of 500 grams (previously newly births were registered from 28 weeks of gestation and a weight of 1000 grams). The increasing value is also induced by the deaths in rural areas caused by the worse conditions of life, the general cultural and sanitary levels, 
the low accessibility to medical services. In 2015 the infant mortality rate was of $9.7 \%$, $0.1 \%$ higher than in the previous year $(2014-9,6 \%$ o).

The life expectancy at birth is also very important in analysing population's health quality, because it represents a synthetic demographic indicator of the population health, which summarizes other demographic indicators, for example the mortality rate, morbidity, and also the economic and social living conditions of a society. During the period 1990-2015, the Republic of Moldova experienced a tendency of increase in the life expectancy at birth. However, the level of economic development in the country brings about lower values of the life expectancy at birth in comparison to other better economically developed countries in Europe, where the average is of about 78-83 years old in 2015. For example, in west European countries the average is of 80 years old, Switzerland recording the highest value of the life expectancy at birth (81 years old for men and 85 for women (prb.org, accessed 20.09.2017)). The evolution of the life expectancy at birth was decreasing between 1990 and 1995 (by 2 years for both genders). This fact was influenced by the difficult economic and social period in the Republic of Moldova. After 1996, the value of life expectancy at birth rose up to 71 years in 2015 (67 years old for men and 75 for women). This positive dynamics is due to some better living conditions, better medical assistance, better alimentation etc. The value of men's life expectancy at birth registered lower values for the last 2 years, from 68 years to 67 years. This fact once again proves the higher vulnerability of men in comparison with women.

After analysing each indicator separately, it is necessary to analyse the overall level of the population's health state. In this way it was determined the Population Health Index, as an integrated indicator. It's important to calculate this index because each indicator analysed separately will describe only a part of a population's characteristics - in this case of the population's health. The index will elucidate more correctly the population health level. After determining it and other indexes from the category of population quality (the Education Index, The demographic index, the Cultural Index), it will be calculated the Population Quality Index, which reflects the level of population quality in the country. The Population Health Index represents the arithmetical mean of three structural indexes: the mortality rate index, the infant mortality index and the life expectancy at birth index. This arithmetical mean will describe key aspects of population health much more completely and will reflect population's health components much more comprehensively.

Analysing the graph of the evolution of the population health index in the Republic of Moldova, it can be noticed that between 1990 and 1995 there a decrease by 0.484 units or $88.9 \%$. As previously explained, it was a difficult period from many points of view: economic, demographic and social. These are the factors that conditioned the rapid decrease of the population health during the first 5 years from the independence. 


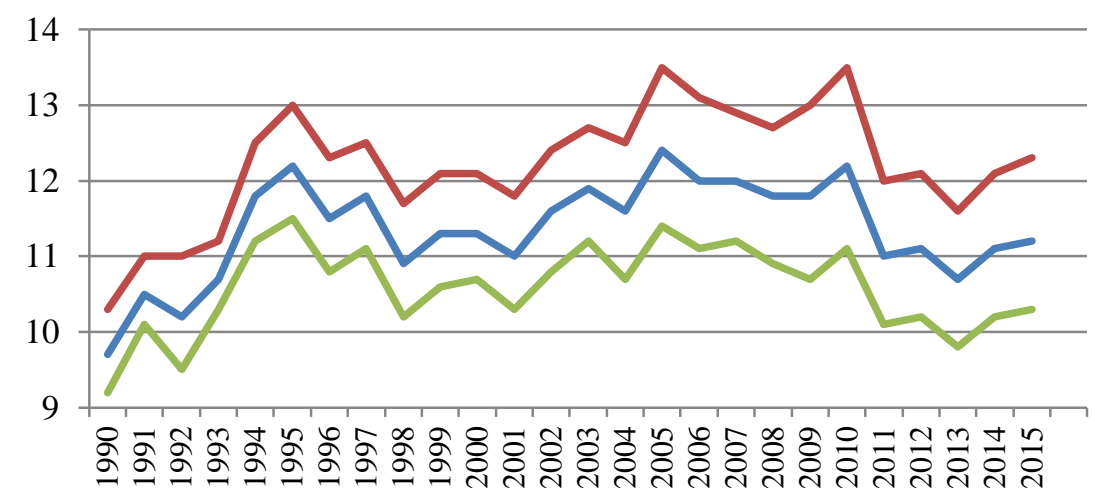

Both Male Female

Fig.1: Mortality rate by gender in the Republic of Moldova, 1990-2015, \%o (Source: NBS)

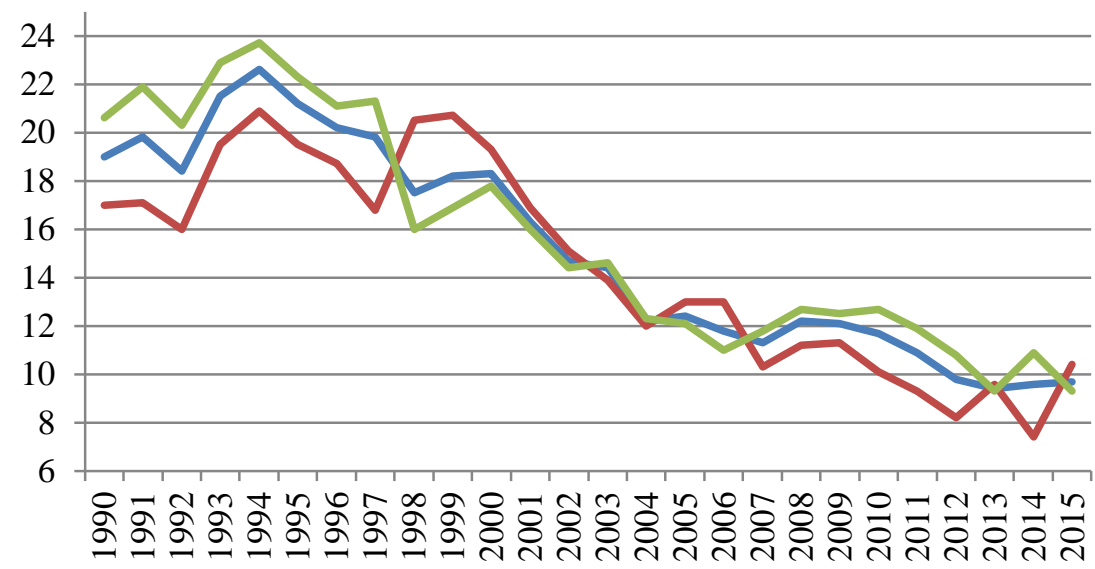

Total - Urban Rural

Fig.2: Infant mortality rate in the Republic of Moldova, 1990-2015, \%o. Source: NBS

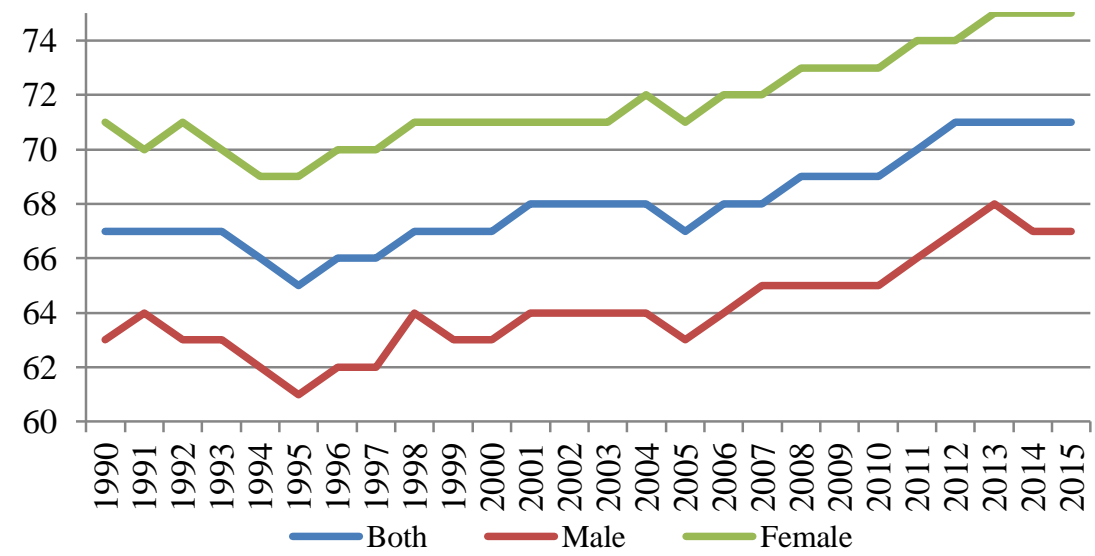

Fig.3: Life expectancy at birth in the Republic of Moldova, 1990-2015. Source: NBS 
Starting with 1996, the health level of the population continuously increased, with little differences in some years. The general trend shows an increase from 1995 to 2013 by 0.816 units or $93.15 \%$. This process of continuous rise tells us about the improvement of the health system, of the health services and the enlargement of medical services. This bigger number of medical services provided by the health system in the country is supported by the financial foreign support for acquiring necessary technologies, also for doctors' qualification and improved conditions for their training. Other causes for a better level of the population's health are the better conditions of life, also of alimentation and water supply. However the general trend of the last 2 years is slightly decreasing (by 0.125 units or $14.26 \%$ ) - fig. 4 . However, it is not a rapid decrease we cannot draw conclusions since the period of time is so short. So, this subject remains one of future interest in order to draw proper conclusions and forecasts.

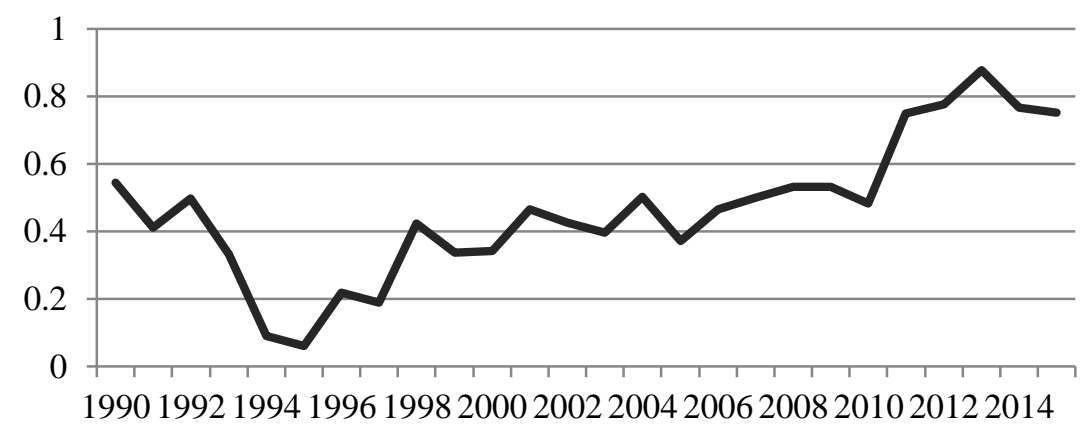

Fig.4: The population health index in the Republic of Moldova, 1990-2015, units. Source: calculated by author

Another aim of this study was the territorial analysis of the population health in the Republic of Moldova. In this way, the health index was calculated for each district of the country for two years (for comparison purposes). The analysis of the two maps of the health index reveals that a high level of population's health is registered in only two districts: Bălți and Chișinău, in both years. This fact is determined by the position of these two districts near the biggest cities and municipalities of the Republic of Moldova, where the conditions of life, work, and medical assistance is better than in other regions of the country. This value is preserved for both years. Most districts record medium and low values. For example, in 2010, 15 districts had medium level of population health, but in 2016 - 17 districts had an average level (fig.5). The number of districts with medium level increased on account of the decrease in the number of districts with low and very low levels of population health. So, the number of districts with a low level of population health decreased from 14 in 2010 to 13 in 2016, while the number of districts with a very low 
level was of 4 in 2010 and 3 in 2016. From this short analysis it is clear that most districts in the country (about $43 \%$ ) record a medium level of the population health , the low level being also well represented (40\% in 2010). The high level is registered only by $6 \%$ and the very low level by only $11 \%$. Most part of the territory and people in the Republic of Moldova have a medium and low level of health - about $83 \%$. In 2016, the situation was a little bit different from the year 2010, the medium level comprising $48 \%$ and the low level $37 \%$. So, it is clear that the level of population health increased slowly, a fact which is also noticeable in the evolution analysis (fig.4).
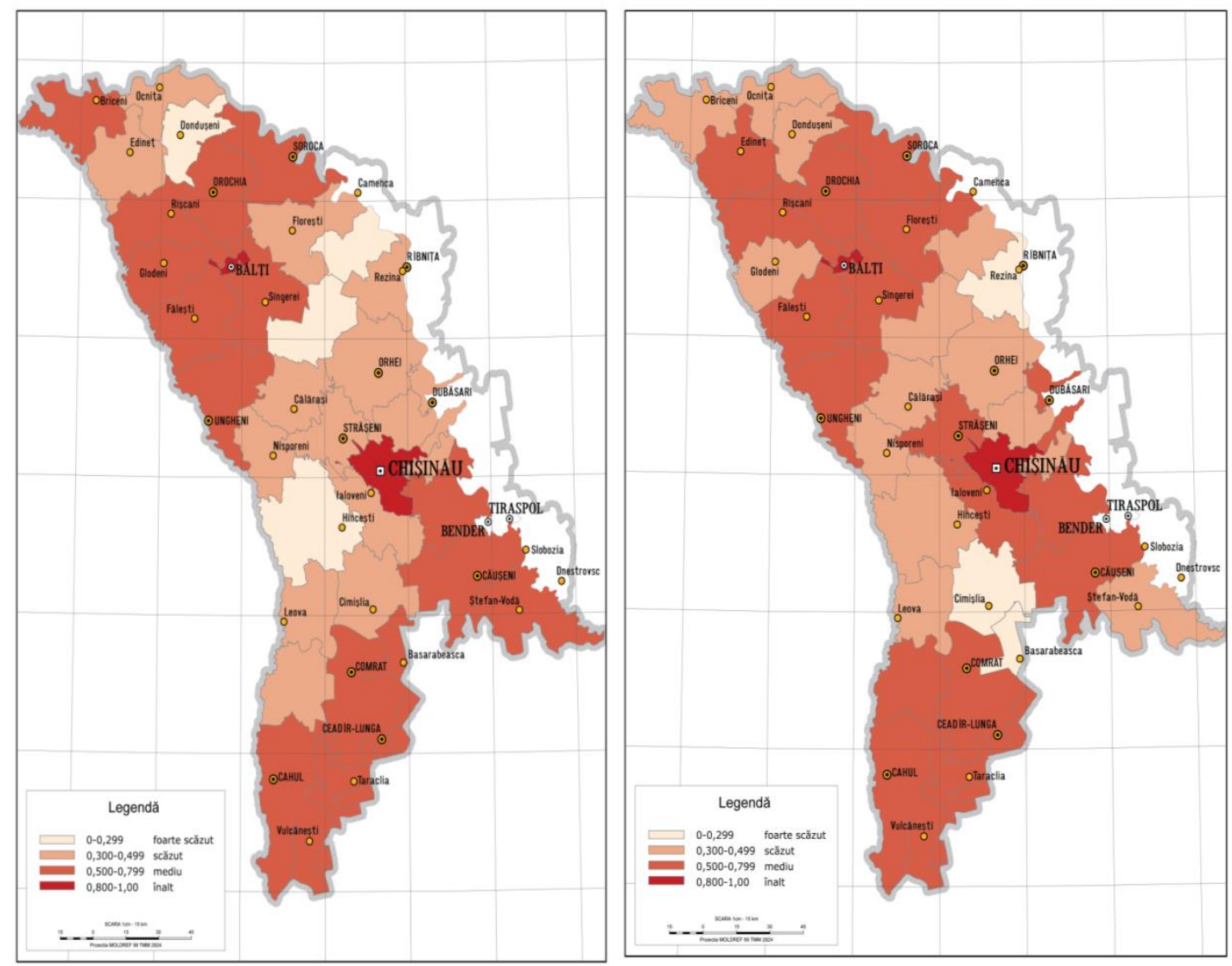

Fig. 5: Population Health Index in the Republic of Moldova, 2010 (A), 2016 (B).

Source: elaborated by author

Making a ranking of the three Development Regions in the Republic of Moldova, the North Region is the first in the top with 1 high level district $(8 \%), 7$ medium level districts (58\%), 4 low level districts (33\%) in 2016. The next Development Region is the South one, with 4 medium level districts $(50 \%), 2$ low level districts (25\%) and 2 very low level districts (25\%). The last region is the Centre 
Region, with 1 high level district (7\%), 5 medium level districts (36\%), and 4 low level districts (50\%) and 1 very low level district (7\%).

\section{Conclusions}

In conclusion, it is important to point out some trends and visible facts about the population health state in the Republic of Moldova:

- The Population Health Index registered a general increasing trend during the analysed period;

- The infant mortality rate index registered the best values, the life expectancy at birth index follows, the mortality rate index being the last;

- Spatially, the population's health quality improved due to the increase in the number of districts with a medium level to the detriment of the number of districts with low and very low levels;

- The number of districts with a high level of the population's health remained of only two: Chișinău and Bălți municipalities.

\section{References}

Biroul NațiONAl De Statistică, Ocrotirea sănătății în Republica Moldova, Chișinău, 2013, 53 p., http://www.statistica.md/public/files/publicatii_electronice/Ocrotirea_sanatatii/Ocroti rea Sanatatii 2013.pdf

Бутов Б.И., Демография. Издательский цеентр Март, Москва - Ростов на Дону, 2003 - 593 ст.

САГРАдОв А.А.,Теория и методы изучения качества населения, Москва, 1995 - 439 ст.

DuMitRACHE, L. Starea de sănătate a populației României. O abordare geografică, București, 2004, $380 \mathrm{p}$.

GrAmA, R., SPINEI, L., BIVOL, A., JEMNA, S., Analiza stării de sănătate a populației Republicii Moldova prin prisma indicatorilor statistici, pentru perioada anilor 2005-2009, Chișinău, 2010, 101 p. Available online at: http://www.undp.md/presscentre/ 2010/Raport PNUD Sanatate 1609 2010.pdf

АогиновА, Н.Н., ЖулинА, М.А. Качество населения: опыт социально демографического исследования// Регионология, 2001 №4, 2002 - 296 - 299 ст. Available online at http://regionsar.ru/sites/default/files/pdf/reg 200142002 1.pdf

MOsK CARL, Making health work: Human Growth in Modern Japan, Berkeley, Calif: University of California Press, 1996 - 156 p.. Available online at : https://books.google.md/books/about/Making_Health_Work.html?id=t8dL114NXaYC \&redir esc $=\mathrm{y}$

SAgRadOV, A.A., Population Quality: Concept and its application to analysis of sociodemographic change in Russia, Statistics in transition, March, 2001, Vol.5, No.1, p. 167-184

Vert CONSTANTIN, Geografia populației.Teorie și metodologie, Editura Mirton, Timișoara, 2001, 208 p., https://geografie.uvt.ro/wp-content/uploads/2015/07/Geografiapopulatiei teorie-si-metodologie.pdf 
*** Maternal Mortality in 2005. Estimates developed by WHO, UNICEF, UNFPA and the World Bank, 40 p., http://www.who.int/whosis/mme 2005.pdf

*** NBS - National Bureau of Statistics, www.statistica.md, accesed 18.09.2017

*** PRB - Population Reference Bureau, www.prb.org, accessed 20.09.2017 